\title{
Endotracheal tube cuff pressure management in adult critical care units in National Hospital of Sri Lanka A baseline audit
}

\author{
ME Maddumage ${ }^{1 *}, A Y A$ Gunasekara ${ }^{2}$, WDD Priyankara ${ }^{1}$ \\ Senior Registrar in Critical Care Medicine ${ }^{1}$, National Hospital of Sri Lanka, Medical officer ${ }^{2}$, Base \\ Hospital, Marawila, Sri Lanka
}

Corresponding author:edirimanoj79@gmail.com

\begin{abstract}
Proper management of endotracheal cuff pressure is pivotal, not only to prevent complications like tracheal mucosal damage and micro aspirations but for efficient positive pressure ventilation. A prospective descriptive study was performed to examine the prevailing practices of endotracheal cuff pressure management (CPM) in adult intensive care units (ICUs) of the National Hospital of Sri Lanka. The auditors visited the ICUs without a prior warning and the CPM was assessed and the endotracheal cuff pressure (CP) was measured using an analogue manometer. Seventy four percent out of total of 50 patients examined had suboptimal cuff pressure recordings and $30 \%$ of them had alarmingly high pressures. Overall practice including documentation (14\%), frequency $(14 \%)$ and the method of CPM (20\%) was significantly unsatisfactory warranting prompt measures to uplift the standards and prevent adverse consequences.
\end{abstract}

Keywords: endotracheal cuff pressure; intensive care unit; manual compression method; minimal leak test; minimal occlusive volume

\section{Background}

Measurement of endotracheal cuff pressure (CP) in ICUs is often not routine. Proper management of $\mathrm{CP}$ is crucial in intubated and mechanically ventilated patients. Adequate sealing of the extraluminal airway in endotracheally intubated patients is important to allow efficient positive pressure ventilation and to avoid micro-aspiration of subglottic secretions potentially causing ventilator associated pneumonia (VAP). In contrast, the excessive $\mathrm{CP}$ can cause mucosal ischaemia leading to tracheal stenosis or tracheaoesophageal fistulae. High-volume low-pressure cuffs (HVLP) were introduced in the early 1970s to enable tracheal wall pressure control. Nevertheless, the use of a HVLP cuff does not guarantee an acceptable mucosal pressure unless the $\mathrm{CP}$ is maintained at $20-30 \mathrm{cmH}_{2} \mathrm{O}^{1}$ This prospective audit was designed to examine the CP management in ICUs of the National Hospital of Sri Lanka which is the largest teaching hospital in the region.
General objective: To examine the tracheal tube cuff pressure management in patients admitted to intensive care units in National Hospital of Sri Lanka.

Proposed standard or target for best practice - $100 \%$ of the time CP should be measured and documented 4-6 hourly

- $100 \%$ of the time cuffs should be correctly inflated to a CP of $20-30 \mathrm{cmH}_{2} \mathrm{O}$ or minimum pressure required to prevent a leak.

\section{Methodology}

A baseline audit was performed in adult intensive care units of the National Hospital of Sri Lanka (NHSL). All the adult patients who are intubated by someone other than the authors and ventilated during the study period were included. Patients who were less than 16 years, with tracheotomies, laryngeal disease or laryngeal surgery and those who were having airway deformities were excluded from the study.

A brief pilot study was performed to establish usability of the data sheet. The auditors visited the

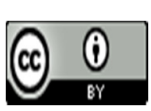

(C) 2017. Maddumage et al. This is an Open Access article distributed under the terms of the Creative Commons Attribution License (http: //creativecommons.org/licenses/by/4. 0), which permits unrestricted use, distribution, and reproduction in any medium, provided the original work is properly credited 
ICU without warning during the period from $01 / 04 / 2015$ to $15 / 05 / 2015$ and the endotracheal tube cuff pressures were measured by themselves using an analogue manometer. At the same time, the method of recording the $\mathrm{CP}$ by the nursing staff at the beginning of the shift and other relevant information was noted. The ventilator settings, size of the tube and peak airway pressure as well were recorded in a data sheet which was based on the standard recommendations for the cuff pressure management (CPM).

\section{Results}

Cuff pressure management was examined in 50 patients admitted to ICUs in NHSL during the study period. (Table 1)

Table 1: Patient characteristics

\begin{tabular}{|l|l|}
\hline & Number (\%) \\
\hline Age (years) & $48 \pm 16.9$ \\
\hline Gender & \\
Male & $35(70 \%)$ \\
Female & $15(30 \%)$ \\
\hline BMI & \\
$<18$ & $4(8 \%)$ \\
$18-23$ & $28(56 \%)$ \\
$>23$ & $18(36 \%)$ \\
\hline Mode of ventilation & \\
CMV & $5(10 \%)$ \\
SIMV & $25(50 \%)$ \\
Spont. & $12(24 \%)$ \\
T-piece & $8(16 \%)$ \\
& \\
\hline ET tube size & \\
$6.5 \mathrm{~mm}$ & $1(2 \%)$ \\
$7.0 \mathrm{~mm}$ & $7(14 \%)$ \\
$7.5 \mathrm{~mm}$ & $22(44 \%)$ \\
$8.0 \mathrm{~mm}$ & $19(38 \%)$ \\
$8.5 \mathrm{~mm}$ & $1(2 \%)$ \\
\hline ICU stay (days) & $4.2 \pm 3.9$ \\
\hline
\end{tabular}

Majority of the patients were males and the favourite ventilatory mode was synchronised intermittent mandatory ventilation (SIMV).

The majority of the patients belonged to the trauma ICUs, as shown below. (Figure 1)
Figure 1: Breakdown of the patients according to the ICU

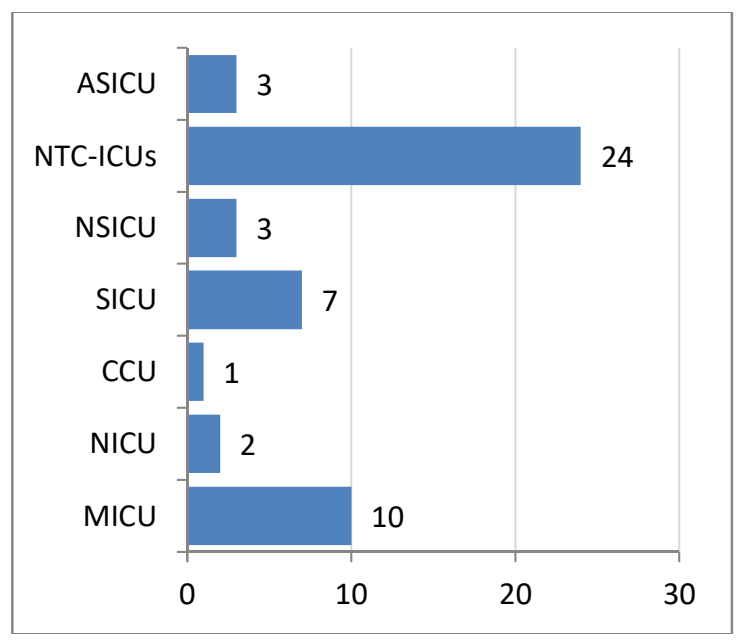

Table 2: Cuff pressure levels

\begin{tabular}{|l|l|l|}
\hline $\begin{array}{l}\text { Cuff } \\
\text { pressure }\end{array}$ & $\begin{array}{l}\text { Number of } \\
\text { patients }\end{array}$ & Percentage \\
\hline$<20 \mathrm{cmH}_{2} \mathrm{O}$ & 14 & $28 \%$ \\
\hline $20-30 \mathrm{cmH}_{2} \mathrm{O}$ & 13 & $26 \%$ \\
\hline$>30 \mathrm{cmH}_{2} \mathrm{O}$ & 23 & $46 \%$ \\
\hline
\end{tabular}

The CP recorded in 23 (46\%) of them exceeded the recommended limit with $11 \quad(22 \%)$ measurements above $50 \mathrm{cmH}_{2} \mathrm{O}$. (Table 2) Twenty eight percent (14) of the sample had inadequate inflation of cuff pressure. This indicates that $74 \%$ of the patients had suboptimal CPM during intensive care in the NHSL.

Table 3: Method of cuff pressure measurement

\begin{tabular}{|l|l|}
\hline $\begin{array}{l}\text { Method of cuff pressure } \\
\text { measurement }\end{array}$ & Number \\
\hline Manual compression & $43(86 \%)$ \\
\hline Minimal leak test (MLT) & 0 \\
\hline Minimal occlusive volume (MOV) & 0 \\
\hline Cuff pressure measurement(CPM) & $7(14 \%)$ \\
\hline
\end{tabular}

Vast majority (86\%) of the CPM were estimated by manual compression of the pilot balloon and the standard Mallinckrodt Medical hand pressure gauge was used only in $14 \%(\mathrm{~N}=7)$ of the

(C) 2017. Maddumage et al. This is an Open Access article distributed under the terms of the Creative Commons Attribution License (http: //creativecommons.org/licenses/by/4. 0), which permits unrestricted use, distribution, and reproduction in any medium, provided the original work is properly credited 
patients. (Table 3) This was in spite of the availability of the manometer in $82 \%$ of the ICUs.

Only $20 \%(\mathrm{~N}=10)$ of ventilated patients had the $\mathrm{CP}$ measured according to the recommendations whereas $76 \%(\mathrm{~N}=38)$ of cases had unsatisfactory CPM, which was only once a day or when indicated. (Table 4)

Table 4: Frequency of CP measurement

\begin{tabular}{|l|l|}
\hline Frequency & $\mathbf{N}(\boldsymbol{\%})$ \\
\hline Every shift (6 hourly) & $10(20 \%)$ \\
\hline 12 hourly & $4(8 \%)$ \\
\hline Once a day (24h) & $17(34 \%)$ \\
\hline Only when indicated & $19(38 \%)$ \\
\hline Never & 0 \\
\hline
\end{tabular}

Table 5: Documentation of CPM

\begin{tabular}{|l|c|c|}
\hline $\begin{array}{l}\text { Documentation of } \\
\text { CPM }\end{array}$ & $\mathbf{N}$ & $\mathbf{\%}$ \\
\hline Not done & 41 & $83 \%$ \\
\hline Every shift & 7 & $13 \%$ \\
\hline Occasionally & 2 & $4 \%$ \\
\hline At intubation only & 0 & - \\
\hline $\begin{array}{l}\text { After a corrective } \\
\text { measure }\end{array}$ & 0 & - \\
\hline
\end{tabular}

Documentation of the CPM was seen in $14 \%$ $(\mathrm{N}=7)$ of the cases and $5(71 \%)$ out of them had CPM exceeding the safe limits when measured by the auditor. (Table 5) CPM was documented in only 1 out of the 12 ICUs examined. CPM was almost always performed by the nursing staff and medical officers were involved very occasionally.

Unfortunately, the CPM is suboptimal in the vast majority of the patients irrespective of the different categories of ICUs. (Table 6) Interestingly, the $\mathrm{CP}$ level was satisfactory in only one patient cared in the only ICU where the cuff pressure was documented every shift (6 hourly) according to the local protocol.
Table 6: CPM according to the category of ICU

\begin{tabular}{|l|c|c|c|}
\hline & Safe CP & $\begin{array}{c}\text { Low } \\
\text { CP }\end{array}$ & High CP \\
\hline Medical ICUs & $3(23 \%)$ & $5(38 \%)$ & $5(38 \%)$ \\
\hline Surgical ICUs & $1(10 \%)$ & $4(40 \%)$ & $5(50 \%)$ \\
\hline Trauma ICUs & $8(29 \%)$ & $6(22 \%)$ & $13(48 \%)$ \\
\hline
\end{tabular}

\section{Discussion}

Best practice guidelines suggest that cuff pressure has to be maintained at $20-30 \mathrm{cmH}_{2} \mathrm{O}$ for a better outcome. ${ }^{1}$ A study of a 10-bed CCU in Australia with 101 patients confirmed that cuff pressure $<20$ $\mathrm{cmH}_{2} \mathrm{O}$ was associated with an increased risk of aspiration, and the incidence of tracheal stenosis was common with cuff pressures $>30 \mathrm{cmH}_{2} \mathrm{O}$. However, despite these best evidence majority of the ICUs in NHSL were neither equipped with local protocol or a dedicated space in the daily nursing charts for regular documentation of CPM.

A study of 85 endotracheally intubated patients in intensive care unit and post anaesthesia care unit found that patients in these areas typically had excessively high ET tube cuff pressures. More than fifty percent of ICU patients had reported pressures $>30 \mathrm{mmHg} .{ }^{3}$ Wujtewicz et al found in an audit done on 107 ITU patients monitoring tracheal tube cuff pressure, that the over inflation is more frequent than under inflation in their study group. ${ }^{4}$ An audit done in the department of anaesthesia, the Queen Elizabeth Hospital, King's Lynn, UK showed that the mean cuff pressure in the study group was $62 \mathrm{cmH}_{2} \mathrm{O}$ and $20 \%$ of the CPs were above $100 \mathrm{cmH}_{2} \mathrm{O}^{5}$

The demonstration of the low accuracy of finger palpation estimates for cuff pressure makes it more appropriate to use a more objective approach for $\mathrm{CPM}^{6}{ }^{6} \mathrm{CPM}$ with an aneroid manometer, recommended as best practice by several studies, provides an objective measurement of cuff pressure that does not involve cuff deflation, potentially decreasing the risk of aspiration. ${ }^{1}$ Even though the analogue manometer was available for majority of the patients, palpation method was opted by the nursing staff in this study with an alarming inaccuracy.

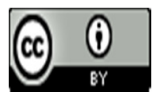

(C) 2017. Maddumage et al. This is an Open Access article distributed under the terms of the Creative Commons Attribution License (http: //creativecommons.org/licenses/by/4. 0), which permits unrestricted use, distribution, and reproduction in any medium, provided the original work is properly credited 
This audit attempted to examine the potential correlation between the CPM and the factors (e.g; mode of ventilatory support, peak inspiratory pressure (PIP), peak end expiratory pressure (PEEP), size of the endotracheal tube, day of intubation, demographic data etc..) that may affect the CP using the Pierson's correlation. However, this did not show any linear relationship probably due to the limited sample size and the unsatisfactory management of the CPM.

Audit Limitations include the overall sample size obtained during the audit period is small precluding assessment of the impact of various factors e.g: PEEP, PIP. ETT size, etc. Differing practices in ICUs were difficult to ascertain as the measurements outside the reference range numbers were limited. Enhanced validity would have been achieved by increasing the duration of the audit period.

\section{Audit Recommendations}

Results of the study to be discussed with relevant departments to raise awareness and encourage ongoing practice improvement. Patients would benefit from further audit cycles over an increased period to improve reliability of good practice. Incorporation of cuff pressure monitoring and measurement within a checklist system is a timely need. This would be best done at the start of each nursing shift as part of a formal check process.

\section{Conclusion}

Vast majority of the intubated patients in ICUs had suboptimal CP recordings and 30\% of them had alarmingly high pressures. Overall practice was unsatisfactory and particular attention should be paid in terms of the proper documentation, adequate frequency and the optimal method of CPM. Prompt measures to optimise CPM would be of paramount importance to uplift the standards and prevent adverse consequences.

\section{References}

1. Lorento L, Blot S, Rello J. Evidence on measures for the prevention of ventilator-associated pneumonia. European Respiratory Journal 2007;30 (6):1193-1207.

https://doi.org/10.1183/09031936.00048507

PMid:18055704
2. Nseir S, Brisson H, Marquette C, et al. Variations in endotracheal cuff pressures in intubated critically ill patients: prevalence and risk factors. Eur J Anaesthesiol 2009;26(3):229-234. https://doi.org/10.1097/EJA.0b013e3283222b6e PMid: 19244697

3. Braz JRC, Navarro LHC, Takata IH, Junior PN. Endotracheal tube cuff pressure: need for precise measurement. Sao Paulo Med.J. 1999;117:6. https://doi.org/10.1590/S151631801999000600004

4. Wujtewicz MA, Sawicka W, SeinAnand J, Oxczuk R et al. Monitoring of tracheal tube cuff pressure in patients treated in intensive therapy unit and intensive care units. European Journal of Anaesthesiology: 2004; 21: 177. https://doi.org/10.1097/00003643-20040600200642

5. Sathish Kumar S, Young PJ. Over-inflation of the tracheal tube cuff: a case for routine monitoring. Critical Care 2002; 6(Suppl 1):37 https://doi.org/10.1186/cc1736 PMCid:PMC3333695

6. Stewart SL, Secrest JA, Norwood BR, Zachary R. A comparison of endotracheal tube cuff pressures using estimation techniques and direct intracuff measurement. AANA J. 2003;71(6):443-7. PMid:15098531

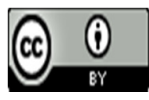

(C) 2017. Maddumage et al. This is an Open Access article distributed under the terms of the Creative Commons Attribution License (http: //creativecommons.org/licenses/by/4. 0), which permits unrestricted use, distribution, and reproduction in any medium, provided the original work is properly credited 